Denis Ignatenko

N.V. Simonova, research supervisor

N.V. Simonova, language adviser

Welding and Electronics Technical School named after Paton, Dnipropetrovsk

\title{
The Environment and its Problems
}

I'm going to speak about the problems of the environment which the world is facing at the moment and what we should do to protect our Earth.

Nowadays, environmental problems are the most burning for the society. Air, water, land and nuclear pollution badly damage the nature. People cut down trees and destroy the habitat of thousands of animals. As a result, many species are in danger of extinction. Factories pollute our rivers and lakes with dangerous chemicals. The increasing number of cars in towns and cities has led to the growth of harmful gases in the atmosphere. There is much litter everywhere, our parks and forests are full of rubbish.

Scientists believe that the problem of global warming is becoming more and more serious. The results of human activity such as acid rains, greenhouse effect and ozone layer destruction cause the changes of the climate on our planet and destroy it. All these facts have a bad influence on our health. More and more people suffer from allergies and breathing problems. It's almost impossible to find a healthy person nowadays.

People are becoming more and more aware that our planet is under threat and it's all our fault. Fortunately, it's not too late to solve these problems. We have the time, the money and the technologies to take care of our planet.

There are a number of simple things we can do if we want to help our planet. For example, if we stop wasting paper and start recycling it, we'll save some of the millions of trees which are cut down every year.

We should also stop making unnecessary car journeys to cut down air pollution. Governments can improve public transport so that people could use it more often. They can also pass laws to stop companies from destroying rainforests. We can create parks for endangered species of animals. People should use natural resources in a rational way and look for alternative sources of energy such as wind and solar energy.

But the most important thing we must do is to open our eyes and act immediately. The Earth is our home and we should protect and save it for ourselves and for the future generations. 